\title{
Satisfaction with Public Hospital Reform and Associated Factors Among Medical Staff: A Cross-Sectional Survey in Wuhan, China
}

\author{
Siyu Tao ${ }^{1,2}$ \\ Zhiming Jiao $\mathbb{( D}^{3}$ \\ Jinzhu $\mathrm{Xie}^{4}$ \\ Qianyu Wang ${ }^{3}$
}

'Shanghai Jiao Tong University School of Medicine, Shanghai, People's Republic of China; ${ }^{2}$ China Hospital Development Institute, Shanghai Jiao Tong University, Shanghai, People's Republic of China; ${ }^{3}$ School of Medicine and Health Management, Tongji Medical College, Huazhong University of Science and Technology, Wuhan, Hubei, People's Republic of China; ${ }^{4}$ Hubei No. 3 People's Hospital of Jianghan University, Wuhan, Hubei, People's Republic of China
Correspondence: Siyu Tao

Shanghai Jiao Tong University School of Medicine, Shanghai, People's Republic of China; China Hospital Development Institute, Shanghai Jiao Tong University, Shanghai, 200025, People's Republic of China

Tel +8613659887696

Email siyutao@shsmu.edu.cn
Purpose: To assess whether medical staff are satisfied with public hospital reform and its influencing factors.

Methods: A sample of 2000 medical staff from 13 public hospitals in Wuhan were surveyed with a self-administered questionnaire. Descriptive analysis and binary logistic regression were conducted to identify the status of the medical staff's attitude to the reform and the influencing factors.

Results: A total of $61.4 \%$ of medical staff satisfied with the reform and the main reason was the promotion of their practice environment and social status brought by the reform. The logistic regression model indicated that the attitude to the reform of medical staff was positively associated with $9-11$ hours of daily working time (OR $=2.373$, as compared with less than 8 hours), higher income $(\mathrm{OR}=1.966)$, the occupation of the nurse and medical technician ( $\mathrm{OR}=2.196-1.464$ as compared with the doctor) as well as negative attitude towards the effectiveness of reform $(\mathrm{OR}=3.676)$.

Conclusion: More than half of medical staff are satisfied with the public hospital reform, while some still hold negative attitude to the reform because of the extra working hours, low salary and high expectations due to professional characteristics and high input costs (education and time). Thus, in the current epidemic of prevention and control, more attention should be paid to the work pressure and enthusiasm of medical personnel. Administrators should pay attention to increasing income and improving the practicing environment and social status to prevent medical staff from treating reforms negatively.

Keywords: public hospital reform, job satisfaction, hospital administration, health management and policy

\section{Introduction}

Public hospitals refer to non-profit hospitals organized by the government or stateowned enterprises and institutions to achieve specific goals. There are public policies or institutional arrangements for countries around the world to ensure the accessibility and fairness of health services, and to increase the health of their citizens. From an international point of view, since World War II, most countries of the Commonwealth of Nations have implemented a National Health Service providing free medical care for all. ${ }^{1}$ In response to market failures, after many lowincome and middle-income countries got rid of colonial rule, they created a health system with public hospitals as the mainstay. ${ }^{2}$ This public policy has been recognized by the international community, but there are some problems such as low 
efficiency, poor satisfaction and waste of resources. ${ }^{3}$ Since the 1980s, affected by economic crises, rising medical and health costs, and other public sector reforms, as well as the promotion of academic ideas such as public choice theory, neoliberalism, and new public management thoughts, many developed and developing countries have promoted the reform of public hospitals. ${ }^{4,5}$

As the developing country with the largest population and the largest medical service in the world, China has been experiencing rapid changes not only in its economy but also its health care system. China's public hospitals share the best health resources and have the best efficiency and quality of care in China. ${ }^{6,7}$ By the end of 2020, there were 11,870 public hospitals in the country, accounting for $33.5 \%$ of the total number of hospitals; 6.21 million health workers, accounting for $76.6 \%$; 5.09 million beds, accounting for $71.4 \%$; and $77.2 \%$ of bed utilization ratio. ${ }^{8}$ However, such a large medical scale also has various problems, with the growing demand for health level, medical staffs are facing unprecedented pressure and challenges, such as the huge workloads (2.79 billion patient visits, accounting for $84.0 \%$ ), the insufficient welfare of health staff, the increasing cost of health services, etc.

Since China launched a new round of medical reform in 2009, the public hospitals reform has been clearly identified as a key breakthrough area by the national reform plan and the ruling party's major decisions. In 2010, the Ministry of Health and five other ministries and commissions jointly issued the "Guiding Opinions on the Pilot Reform of Public Hospitals" which focused on maintaining the public welfare of public hospitals. In 2015 , the pilot program for comprehensive reform of urban public hospitals was further expanded. Comprehensive reform of urban public hospitals, which revolved around the construction of a modern hospital management system, a conversion compensation mechanism for the "cancellation of drug addition, reduction of drug and consumables purchase price, and improvement of labor price" and a service system, was fully implemented by $2017 .{ }^{9}$

Previous studies of public hospital reform focused on two aspects, as follows. First, the impact of the reform on medical expenses. Huang investigated the attitudes and opinions of directors of public hospitals regarding reform policies and revealed that the reform related to the hospital financial position ranked first in the list of concerns expressed by directors. ${ }^{10}$ The public hospital reform called for increasing service charges and eliminating the markup on prescriptions, with the hope of improving the quality of care and controlling cost inflation. ${ }^{11}$ But previous research has suggested that overall health care costs did not decrease. ${ }^{12,13}$ Yip reviewed the course of China's medical reform in the past 10 years and believed that, although the Zero-Markup Drug Policy reduced drug expenditures, the diagnostic tests and basic medical services were increasing. ${ }^{14}$ Second, the impact of the reform on hospital management. The policy clarified the separation of government administration from hospital management, and separated the regulatory authorities from the operational management entities. ${ }^{15} \mathrm{Li}$ thought that hospital directors will be allocated more management power and will become more autonomous in personnel management through the reform. ${ }^{16}$ Sheng Nong examined the reasons behind stymied public hospital governance reform. The study found that the hospital administrators have high expectations for the public hospital reform, but they felt the reform lacks operability. ${ }^{17}$

Previous studies focused on medical expenses and hospital management, which may neglect the welfare of medical staff. Medical staff are the core resource of public hospitals, and they are the executor and practitioner who implement the objectives and tasks of the medical reform policy. ${ }^{18}$ There is a consensus that the medical staff's attitude toward public hospital reform is one of the essential elements of occupational health and a key indication of reform effectiveness. ${ }^{19}$ Reform satisfaction is a subjective evaluation by medical staff which reflects their emotional state about the reform after a comparison between the perception of medical reform and the expectation of it, and it is also an important factor affecting the enthusiasm of medical personnel. Being satisfied by medical staff, stimulating the vitality and mobilizing the enthusiasm of medical staff are the driving forces for the public hospital reform. In addition, the satisfaction of medical staff with reform, as the direct providers of health care, ensures the quality of medical reform and stabilizes the medical services provided by public hospitals. ${ }^{20}$ Although the medical reforms in various countries have begun to pay attention to the satisfaction of medical personnel and adopted relevant policies to improve, research shows that there is still a certain gap between the current status of medical staff satisfaction and the ideal level. ${ }^{21,22}$

Therefore, the purpose of this study was to explore the status quo of the satisfaction of medical staff with public hospital reform in China and what kind of efforts can promote medical staff's acceptance of the reform. The 
findings of such a study may provide empirical evidence of the reform satisfaction of different medical staff for relevant international research and provide evidence and support for the reconstruction of improved enthusiasm of medical staff so that they actively participate in reforms.

\section{Materials and Methods}

\section{Participants and Study Design}

This cross-sectional survey was implemented from September to October 2017 in the city of Wuhan, the capital of Hubei Province, which is the largest city of Central China. As a national center city and national medical center, ${ }^{23}$ Wuhan is rich in medical resources and its economic development level is at a medium level. There are many public hospitals with various affiliations and levels. Wuhan initiated the comprehensive reform of public hospitals in $2015 .{ }^{24}$ As of June 2017, the reform has been implemented in all types of national, provincial, municipal, district and military public hospitals in Wuhan. The reform of public hospitals in Wuhan is relatively mature and stable, which can accurately reflect the effect of China's health care reform policy. We believe that this survey is representative of the reform of public hospitals in China.

The sample population was selected using a multistage stratified random sampling process. In the first stage, we stratified hospitals according to their affiliation. To make the sample more representative, the stratum of hospitals included those administered by the national, provincial, municipal, district and military health commissions. Thirteen hospitals were selected, which included general and specialized hospitals. In the second stage, the sample group was selected from the hospitals by simple random sampling, that is, 200 medical staff were randomly selected per general provincial and municipal hospital and 100 medical staff per specialty and district hospital. Medical staff included doctors, nurses, and medical technicians (personnel in pharmacy, clinical laboratory, and radiology department). The number of participating medical staff was proportional to the size of population. Then, the selected medical staff completed self-administered anonymous questionnaires with the assistance of the Wuhan City Health and Family Planning Commission for this investigation. Finally, questionnaires were distributed to 2122 subjects; of those, 2000 subjects provided complete data and were included in the analysis. This study was performed in accordance with the principles of the
Declaration of Helsinki and was approved by the Ethics Committee of Tongji Medical College, Huazhong University of Science and Technology (IORG No: IORG0003571). All participants in the study were voluntary and provided written informed consent before participating in this survey. Their privacy was strictly protected by filling in the questionnaires anonymously.

\section{Measurements/Questionnaire}

Based on a review of previous literature and expert consultation, the questionnaire consisted of three parts. Part 1 included sociodemographic information, Part 2 included working situation and Part 3 was medical staff's overall satisfaction and factors related to this satisfaction. Through reliability statistics, Cronbach's alpha was 0.896 .

Part 1 included sociodemographic information of medical staff, including age, gender, years of employment, technical category, department, educational background, and professional title. The professional title in Chinese medical institutions can be divided into three classes: senior/deputy senior, intermediate, primary and lower than primary. ${ }^{25}$ The senior/deputy senior staff member is equivalent to the manager or the supervisor. The intermediate staff member is a team leader. The primary staff member is a normal staff member and the staff member with a title lower than primary professional is a trainee.

Part 2 covered two aspects of the working situation: the working situation at present (daily working hours and monthly income) and the change experienced after reform (working hours change and monthly income change). For the number of daily working hours, three options were provided by " $\leq 8 \mathrm{~h}$ ", “9h-11h" and " $\geq 12 \mathrm{~h}$ " according to Chinese statutory 8 hours of working time per day.

Part 3 investigated overall satisfaction (eg "Are you satisfied with the present reform?") and factors related to reform satisfaction, such as "performance appraisal system", "hospital management", "salary system", and "effectiveness of reform"). For these aspects, five options (numbered from 1 to 5 ) were provided to express degree of satisfaction: 1 , very satisfied; 2 , satisfied; 3 , moderately/ acceptably satisfied; 4 , dissatisfied; and 5 , very dissatisfied, referring to the design idea of the Likert scale.

In addition, respondents were asked about their attitude to this reform and their reasons.

\section{Statistical Analysis}

EpiData3.1 was used to establish a database, and double machine inputting method was performed to enter the 
collected data into the computer. All analyses were performed with the statistical software SPSS 22.0 (IBM Corp., Armonk, NY, USA). Descriptive analyses were conducted on demographic factors and the reasons for satisfaction and dissatisfaction. Age was described using mean values (SD). Medical staff's work situation and job satisfaction were analyzed by proportions. Pearson chi-square tests were conducted to compare job satisfaction between groups such as those in different hospitals, departments and technical categories, individual satisfaction with performance appraisal system, hospital management, salary system, and effectiveness of reform. Mantel-Haenszel chi-square tests were employed to evaluate the relationship between the attitude and the rank work-related variables (hospital grade, educational background, years of employment, professional title, daily working hours, daily working hours change, monthly income, monthly income change). The significant factors identified using the Pearson chi-square test and MantelHaenszel chi-square test were entered into a binary logistic regression (BLR) model $(P<0.05)$. The BLR model used overall job satisfaction as the dependent variable: 1 , satisfied; 0 , dissatisfied. Odds ratios (ORs) are reported with 95\% confidence intervals (CIs), where appropriate. For all analyses, two-sided $\mathrm{P}<0.05$ was considered significant.

\section{Results}

\section{Participants' Characteristics}

Basic information on respondents is tabulated in Table 1, with the number $(\mathrm{N})$ and the corresponding percentages. Of the 2000 participants, the investigated medical staff members were mainly comprised of females (65.7\%). The largest proportion of respondents ranged in age from 30 to 39 years (40.6\%). The average age of the respondents was 34.30 \pm 8.49 years. The majority of the respondents had more than 10 years of employment (41.4\%). Respondents' average years of employment were $10.47 \pm 9.26$ years. Most participants had an excellent educational background; $41.3 \%$ of participants had a master's degree and above. Most respondents had primary professional title (44.25\%), followed by intermediate professional title $(33.20 \%)$. The majority of respondents were doctors $(50.0 \%)$, while $30.0 \%$ were nurses and $20.0 \%$ were medical technicians.

\section{Medical Staff's Attitude Towards Public Hospital Reform and the Related Factors} Whether reform satisfied medical staff according to demographic characteristics and work-related characteristics
Table I Demographic Characteristics of the 2000 Sampled Medical Staff

\begin{tabular}{|c|c|c|}
\hline Demographic Characteristics & $\mathbf{N}$ & $\%$ \\
\hline Age (mean \pm standard deviation) & $34.30 \pm 8.50$ & \\
\hline \multicolumn{3}{|l|}{ Gender } \\
\hline Male & 685 & 34.25 \\
\hline Female & 1315 & 65.75 \\
\hline \multicolumn{3}{|l|}{ Age group } \\
\hline 29 and below & 693 & 34.65 \\
\hline $30-39$ & 812 & 40.6 \\
\hline $40-49$ & 353 & 17.65 \\
\hline 50 and above & 142 & 7.1 \\
\hline \multicolumn{3}{|l|}{ Years of employment } \\
\hline $0-4$ & 664 & 33.2 \\
\hline $5-9$ & 508 & 25.4 \\
\hline$\geq 10$ & 828 & 41.4 \\
\hline \multicolumn{3}{|l|}{ Technical category } \\
\hline Doctors & 1000 & 50 \\
\hline Nurses & 600 & 30 \\
\hline Medical technicians & 400 & 20 \\
\hline \multicolumn{3}{|l|}{ Department } \\
\hline Internal medicine & 484 & 24.2 \\
\hline Surgery & 347 & 17.35 \\
\hline Other & 1169 & 58.45 \\
\hline \multicolumn{3}{|l|}{ Educational background } \\
\hline Master's degree and above & 826 & 41.3 \\
\hline Bachelor's degree & 894 & 44.7 \\
\hline Junior college and below & 280 & 14 \\
\hline \multicolumn{3}{|l|}{ Professional title } \\
\hline Senior/deputy senior & 316 & 15.8 \\
\hline Intermediate & 663 & 33.2 \\
\hline Primary & 885 & 44.25 \\
\hline Lower than primary & 136 & 6.8 \\
\hline
\end{tabular}

is shown in Table 2. Among all 2000 medical staff, more than half $(61.40 \%)$ were satisfied with the reform. Of all participants, $80 \%$ were in the general hospital, $7.6 \%$ worked for more than 12 hours per day, more than half (51.1\%) had junior titles or less and had worked for less than 10 years, accounting for $51.1 \%$ of the total number of working years. The proportion of participants feeling the pressure of the performance appraisal system was $86.3 \%$. Most people were satisfied with the hospital management after health care reform, but more people were dissatisfied with the salary system than were satisfied. From Table 2, we can see that participants who were dissatisfied with hospital management and the salary system were not satisfied with the reform. Pearson chi-square tests and 
Table 2 Association Between Demographic Characteristics, Work-Related Characteristics, and the Satisfaction of Medical Staff with the Reform $(\mathrm{N}=2000)$

\begin{tabular}{|c|c|c|c|c|c|c|}
\hline \multirow[t]{2}{*}{ Variables } & \multicolumn{2}{|c|}{ All Subjects } & \multicolumn{2}{|c|}{ Satisfaction with the Reform } & \multirow[t]{2}{*}{ Chi-Square } & \multirow[t]{2}{*}{$P$ value } \\
\hline & $\mathbf{n}$ & $\%$ & Yes (\%) & No (\%) & & \\
\hline Number of medical staff & 2000 & 100 & 61.4 & 38.6 & & \\
\hline Categories of hospital & & & & & 0.279 & 0.597 \\
\hline General hospital & 1600 & 80 & 61.1 & 38.9 & & \\
\hline Specialized hospital & 400 & 20 & 62.5 & 37.5 & & \\
\hline Hospital grade & & & & & $46.27^{\Delta}$ & $<0.01 *$ \\
\hline Ministry hospital & 400 & 20 & 60.3 & 39.7 & & \\
\hline Provincial hospital & 700 & 35 & 65.3 & 34.7 & & \\
\hline Municipal hospital & 600 & 30 & 56.3 & 43.7 & & \\
\hline District hospital & 200 & 10 & 52 & 48 & & \\
\hline Enterprise hospital & 100 & 5 & 87 & 13 & & \\
\hline Department & & & & & 14.05 & $<0.01 *$ \\
\hline Internal medicine & 484 & 24.2 & 68.2 & 31.8 & & \\
\hline Surgery & 347 & 17.3 & 62 & 38 & & \\
\hline Others & 1169 & 58.5 & 58.3 & 41.7 & & \\
\hline Technical category & & & & & 175.7 & $<0.01 *$ \\
\hline Doctors & 1000 & 50 & 74.7 & 25.3 & & \\
\hline Nurses & 600 & 30 & 54.3 & 45.7 & & \\
\hline Medical technicians & 400 & 20 & 38.5 & 61.5 & & \\
\hline Educational background & & & & & $82.71^{\Delta}$ & $<0.01 *$ \\
\hline Master's degree and above & 826 & 41.3 & 71.3 & 28.7 & & \\
\hline Bachelor's degree & 894 & 44.7 & 58.3 & 41.7 & & \\
\hline Junior college and below & 280 & 14 & 41.8 & 58.2 & & \\
\hline Years of employment & & & & & $11.2 \mathrm{I}^{\Delta}$ & $<0.01 *$ \\
\hline $0-4$ & 664 & 33.2 & 65.8 & 34.2 & & \\
\hline $5-9$ & 508 & 25.4 & 62 & 38 & & \\
\hline$\geq 10$ & 828 & 41.4 & 57.4 & 42.6 & & \\
\hline Professional title & & & & & $0.164^{\Delta}$ & 0.69 \\
\hline Senior title & 316 & 15.8 & 64.6 & 35.4 & & \\
\hline Middle title & 663 & 33.2 & 59.3 & 40.7 & & \\
\hline Junior title or less & 1021 & $5 \mathrm{I} .1$ & 61.7 & 38.3 & & \\
\hline Working hours/day & & & & & $4.54^{\Delta}$ & $0.03 *$ \\
\hline$\leq 8$ & 1048 & 52.4 & 57.9 & 42.1 & & \\
\hline $9-11$ & 801 & 40.1 & 66.7 & 33.3 & & \\
\hline$\geq 12$ & 151 & 7.6 & 57 & 43 & & \\
\hline \multicolumn{7}{|l|}{ Daily working hours change } \\
\hline Extended & 621 & 31.1 & 63.93 & 36.07 & $7.21^{\Delta}$ & $0.027 *$ \\
\hline Constant & 1254 & 62.7 & 61.08 & 38.92 & & \\
\hline Time reduction & 125 & 6.3 & 51.2 & 48.8 & & \\
\hline Monthly income change & & & & & $5.42^{\Delta}$ & $0.02 *$ \\
\hline Decreased & 298 & 14.9 & 67.8 & 32.2 & & \\
\hline Equal & 1049 & 52.4 & 60.9 & 39.1 & & \\
\hline Increased & 653 & 32.7 & 59.1 & 40.9 & & \\
\hline
\end{tabular}

(Continued) 
Table 2 (Continued).

\begin{tabular}{|c|c|c|c|c|c|c|}
\hline \multirow[t]{2}{*}{ Variables } & \multicolumn{2}{|c|}{ All Subjects } & \multicolumn{2}{|c|}{ Satisfaction with the Reform } & \multirow[t]{2}{*}{ Chi-Square } & \multirow[t]{2}{*}{$P$ value } \\
\hline & $\mathbf{n}$ & $\%$ & Yes (\%) & No (\%) & & \\
\hline Does performance appraisal system bring pressure? & & & & & 0.682 & 0.41 \\
\hline A lot & 604 & 30.2 & 63.7 & 36.3 & & \\
\hline A bit & 1122 & 56.1 & 59.8 & 40.2 & & \\
\hline Not have & 274 & 13.7 & 62.4 & 37.6 & & \\
\hline Hospital management & & & & & 450.91 & $<0.01 *$ \\
\hline Satisfied & 1420 & 71 & 76.1 & 23.9 & & \\
\hline Dissatisfied & 580 & 29 & 25.2 & 74.8 & & \\
\hline Monthly income, RMB & & & & & $12.28^{\Delta}$ & $<0.01 *$ \\
\hline$\leq 5000$ & 742 & 37.1 & 57.3 & 42.7 & & \\
\hline $5000-10,000$ & 1024 & 51.2 & 62.4 & 37.6 & & \\
\hline$\geq 10,000$ & 234 & 11.7 & 69.7 & 30.3 & & \\
\hline Salary system & & & & & & \\
\hline Satisfied & 979 & 48.9 & 63.4 & 36.6 & 3.52 & 0.06 \\
\hline Dissatisfied & 1021 & 51.1 & 59.4 & 60.6 & & \\
\hline Can the reform solve problems? & & & & & 213.05 & $<0.01 *$ \\
\hline Yes & 962 & 48.1 & 77.9 & 22.1 & & \\
\hline No & 1038 & 51.9 & 46.1 & 53.9 & & \\
\hline
\end{tabular}

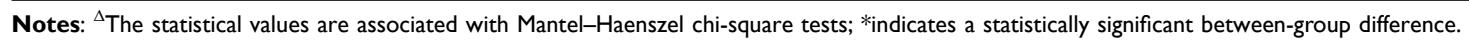

Abbreviation: RMB, renminbi (I RMB $=\$ 0.15)$.

Mantel-Haenszel trend tests showed that most of the variables (including hospital grade, department, technical category, educational background, years of employment, daily work time, performance appraisal, hospital management, monthly income group, and salary system) were closely related with the satisfaction of medical staff with the reform of public hospitals. The probability of satisfaction with the reform was higher in medical staff who worked in provincial hospitals, internal medicine and medical treatment departments, who had a master's degree or above, who had worked for four years or less, who worked 9-11 hours a day, who were satisfied with hospital management, salary system, and those whose monthly income was more than 10,000 yuan. Staff whose monthly income decreased after the reform were less satisfied.

Reasons for satisfaction with the public hospital reform are as follows. For more than a third of participants (37.4\%), better and more stable practicing environment was the primary reason attributed to the reform's popularity with medical staff. Higher social status and sense of accomplishment was the second most important reason $(24.8 \%)$. Third, $16.6 \%$ of the participants were satisfied because the reform has provided them with more training opportunities and advances in titles and personal growth.
Reasons for dissatisfaction with the reform are as follows. Long working hours and hard physical work were the main issues complained about (34.9\%). Relatively low income was the secondary reason chosen by the participants $(32.7 \%)$. Third, $18.6 \%$ of the participants expressed dissatisfaction because they believed that the reform did not reduce their practice risk.

\section{Major Factors Affecting the Attitude of Medical Staff to Public Hospital Reform}

After collinear analysis, independent variables $(\mathrm{r}<0.06)$ with statistical significance $(\mathrm{P}<0.05)$ in the chi-square tests were entered into the binary logistic regression model, with satisfaction $(\mathrm{y}=1)$ or dissatisfaction $(\mathrm{y}=0)$ with the reform being the dependent variables. As indicated in Table 3, significant relationships were found between the attitude of medical staff towards satisfaction with the reform and factors such as technical category, educational background, working hours per day, and changes in working hours before and after the reform, monthly income and cognition of the effectiveness of the reform.

The attitude to satisfaction with the reform of nurses and medical technicians was 2.196-fold higher (OR = 2.196; 95\% CI $=1.581-3.050 ; \mathrm{P}<0.05)$, 1.464-fold higher 
Table 3 Analysis of Multiple Factors Affecting the Satisfaction of Medical Staff with the Reform

\begin{tabular}{|c|c|c|c|c|}
\hline Factors & B & P-value & OR & $(95 \% \mathrm{Cl})$ \\
\hline \multicolumn{5}{|l|}{ Technical category } \\
\hline Doctors & & $<0.001$ & & \\
\hline Nurses & 0.787 & $<0.001$ & 2.196 & $(1.581,3.050)$ \\
\hline Medical technicians & $0.38 I$ & 0.013 & 1.464 & $(1.084,1.978)$ \\
\hline \multicolumn{5}{|l|}{ Department } \\
\hline Internal medicine & & 0.368 & & \\
\hline Surgery & 0.103 & 0.431 & 1.108 & $(0.858, I .430)$ \\
\hline Others & -0.122 & 0.394 & 0.885 & $(0.669,1.172)$ \\
\hline \multicolumn{5}{|l|}{ Educational background } \\
\hline Master's degree and above & & 0.013 & & \\
\hline Bachelor's degree & 0.470 & 0.006 & 1.600 & $(I .144,2.236)$ \\
\hline Junior college and below & 0.383 & 0.010 & 1.467 & $(1.098,1.960)$ \\
\hline \multicolumn{5}{|l|}{ Working hours/day } \\
\hline$\leq 8$ & & $<0.001$ & & \\
\hline $9-11$ & 0.864 & $<0.001$ & 2.373 & $(1.569,3.589)$ \\
\hline$\geq 12$ & 0.298 & 0.156 & 1.347 & $(0.893,2.032)$ \\
\hline \multicolumn{5}{|l|}{ Changes in working hours } \\
\hline Increased & & 0.013 & & \\
\hline Unchanged & 0.651 & 0.003 & 1.918 & $(1.244,2.955)$ \\
\hline Reduced & 0.506 & 0.013 & 1.659 & $(1.111,2.478)$ \\
\hline \multicolumn{5}{|l|}{ Monthly income, RMB } \\
\hline$\leq 5000$ & & $<0.001$ & & \\
\hline $5000-10,000$ & -0.676 & $<0.001$ & 0.509 & $(0.362,0.715)$ \\
\hline$\geq 10,000$ & -0.359 & 0.032 & 1.432 & $(1.032,1.988)$ \\
\hline \multicolumn{5}{|l|}{ Changes in monthly income } \\
\hline Decreased & & 0.166 & & \\
\hline Equal & 0.300 & 0.061 & 1.350 & $(0.987,1.846)$ \\
\hline Increased & 0.063 & 0.571 & 1.065 & $(0.857, I .324)$ \\
\hline \multicolumn{5}{|c|}{ Whether the reform can solve problem } \\
\hline Yes & & & & \\
\hline No & 1.302 & $<0.001$ & 3.676 & $(2.752,4.910)$ \\
\hline Constant & -1.802 & $<0.001$ & 0.165 & \\
\hline
\end{tabular}

Abbreviation: RMB, renminbi (I RMB $=\$ 0.15)$.

$(\mathrm{OR}=1.464 ; 95 \% \mathrm{CI}=1.084-1.978 ; \mathrm{P}<0.05)$ than that of doctors. The attitude to satisfaction of medical staff who had a bachelor's degree, junior college qualification and below was 1.600 -fold higher $(\mathrm{OR}=1.600 ; 95 \% \mathrm{CI}=$ 1.144-2.236; $\mathrm{P}<0.05), 1.467$-fold higher $(\mathrm{OR}=1.467$; $95 \% \mathrm{CI}=1.098-1.960 ; \mathrm{P}<0.05)$ than that of medical staff who had a master's degree and above. The attitude to satisfaction of medical staff who worked 9 to 11 hours per day was 2.373-fold higher than that of medical staff who worked less than 8 hours per day $(\mathrm{OR}=2.373 ; 95 \%$ $\mathrm{CI}=1.569-3.589 ; \mathrm{P}<0.05)$. The attitude to satisfaction of medical staff whose working time remained unchanged or reduced after the reform was 1.918-fold higher $(\mathrm{OR}=$ 1.918; 95\% CI $=1.244-2.955 ; \mathrm{P}<0.05), 1.659$-fold higher $(\mathrm{OR}=1.659 ; 95 \% \mathrm{CI}=1.111-2.478 ; \mathrm{P}<0.05)$ than that of medical staff whose working time increased after the reform. The attitude to satisfaction of medical staff who earned more than 10,000 RMB per month, 5000-10,000 $\mathrm{RMB}$, was 1.966-fold higher $(\mathrm{OR}=1.966 ; 95 \% \mathrm{CI}=$ 1.399-2.761; $\mathrm{P}<0.05), 1.432$-fold higher $(\mathrm{OR}=1.432$; $95 \% \mathrm{CI}=1.032-1.988 ; \mathrm{P}<0.05)$ than that of medical staff who earned less than 5000 RMB per month. The attitude to satisfaction of medical staff who considered that the reform failed to clear "difficulties and high 
expense in medical care" away was 3.676-fold higher than that of medical staff who considered the reform achieved results. There was no significant difference between the monthly income and the monthly income change after the reform $(2=0.237 ; \mathrm{P}=0.994)$.

\section{Discussion}

This study found that the popularity of public hospital reform among medical staff was not high in Wuhan: only $61.4 \%$ of investigated medical personnel expressed satisfaction with this reform, which is similar to the results of the empirical study but far lower than the $80 \%$ satisfaction level requested by the "Hospital Management Evaluation Guide" stipulated by China Ministry of Health. ${ }^{26}$ In addition, according to our logistic regression analysis, factors related to the satisfaction of medical staff with public hospital reform were occupational characteristics of medical staff, such as working hours, income, technical categories and educational backgrounds, the recognition of the effects of reform. A possible explanation for this is that the reform of public hospitals not only impacted the original personnel recruitment, salary management, personnel management systems of the hospital, but also affected the vested interests of individuals. Therefore, medical staff with various occupational characteristics are different in their satisfaction.

Regarding the significant association between the satisfaction of medical staff with the reform and work-related conditions, working hours and income were important predictors of medical staff attitudes to hospital reform. Medical staff whose working hours were unchanged or reduced after reform were found to be satisfied with the reform compared to those whose working hours increased. These findings are also consistent with previous research, and a reduction in people's working hours can directly increase their job satisfaction. ${ }^{27}$ However, it is worth noting that medical staff who worked 9-11 hours a day after the reform had a more favorable attitude about the reform than those who worked less than 8 hours a day; a possible explanation for this might be that the reform has recognized the extra work of medical personnel and increased the performance pay for medical staff. $^{28}$ Similar to previous studies, ${ }^{29,30}$ this research found that higher income has a significant positive impact on the satisfaction of medical staff with reform efforts. This study has further confirmed that, regardless of the magnitude of the change in monthly income before and after the reform, satisfactory high income as a manifestation and recognition of the technical workforce of medical staff is beneficial for winning their support for the reform. $^{31}$
The results showing that the satisfaction of doctors is lower than that of nurses and medical technicians is in line with other studies conducted in China. ${ }^{32,33}$ This kind of emotion from doctors who are not satisfied with the reform is not only related to the professional characteristics of doctors, nurses and medical technicians, but is also inseparable from the contents of hospital reform. ${ }^{34}$ The doctors' education and training cycle is longer than that of the nurses and medical technicians, ${ }^{35}$ and their work is more complicated and changeable. They not only face patients' inquiries and pressures directly, but also face the rapid development of medical technology which requires studying and research outside of working hours. In particular, the reform strengthens doctors' performance responsibility and strict requirements about doctor-patient communication, ${ }^{36}$ so they work in an environment with relatively long working hours and high working intensity which leads them to be dissatisfied with the reform.

Although the reform improved the practicing environment and reflected personal values in the work, the present study showed that medical staff who have a higher level of education are not satisfied with the reform. As a national central city and a national medical and health service center, ${ }^{37}$ Wuhan has a very large patient flow and a large workload for medical and technical personnel. In 2016, a total of 47,509,751 patients received diagnosis and treatment in Wuhan public hospitals, ${ }^{38}$ however, the number of health technicians per 1000 population was $9.13,{ }^{38}$ hospitals in Wuhan have received a lot of patients from other places to illustrate that Wuhan hospitals are facing a great demand for medical services and a large flow of patients.${ }^{39}$ Although the reform is further promoting the development of graded diagnosis and treatment systems and medical partnerships ${ }^{40}$ some doctors operate in high-intensity labor conditions whereby they see more than 100 patients a day, and a comprehensive Chinese survey shows that $50.8 \%$ of health care workers feel overworked. ${ }^{41}$ Facing the huge demand for such medical services, doctors have to manage longer than usual work hours. With the promotion of reform, health care staff with higher academic qualifications usually have more responsibilities and pressures, which contribute to a lower sense of satisfaction. In the current COVID-19 pandemic, the emergency work pressure and working hours of medical staff should be paid more attention to, and the staff can be appropriately adjusted according to the changing trend of the pandemic. It is suggested to increase the special subsidies for pandemic prevention and control from financial funds or public welfare fund for medical staff, or to consider a certain degree of tax concessions. Giving spiritual rewards to medical staff, in the form of spiritual gain, honor and social status, in the 
stage of pandemic prevention and control work is also suggested.

Our results show that the popularity of reform among medical staff who believe that the current reform is successful is low. This finding not only reflects the expectations of medical staff in relation to improving the practice environment and their sense of acquisition through reform but also shows that the biggest problem faced by the reform is the contradiction between the scarcity of medical resources and the infinity of people's demand for health care. The income of medical staff is directly linked to the department income in most public hospitals. ${ }^{10}$ The "zero-addition of drugs" policy, one of the main measures of reform, broke China's long-standing compensation mechanism that "fund[s] public hospitals primarily medicine sales". ${ }^{42}$ Although the present reform has appropriately raised some medical service charges that reflect the value of doctors' technical services, such as diagnosis and surgery, the adjustment of medical service prices and the salary distribution and performance appraisal of doctors have not been unified, ${ }^{43}$ which means that the more doctors research and innovate, the more medical expenses are saved, and the less income the department and individuals receive. This situation greatly reduces the enthusiasm of doctors for reform. Only by separating doctors from the income generation of hospitals can we arouse the enthusiasm of doctors for reform. Therefore, there is an urgent need for the Chinese government to deepen the reform, including trying to improve remuneration packages, practice environment, and social status to stimulate the enthusiasm, initiative, and creativity of medical staff.

\section{Conclusion}

This study found that there was a relatively high proportion of medical staff not welcoming the public hospital reform in Wuhan, China, and the main reasons were excessive working hours and lower wages. Additionally, factors in the study related to the satisfaction of medical staff with hospital reform according to logistic regression analysis were the technical category, educational background, working hours, income, and satisfaction with the practical effects of this reform. From the results, in the current pandemic prevention and control, more attention should be paid to the work pressure and enthusiasm of medical personnel and policy makers should pay more attention to increasing income and improving the practicing environment and social status to prevent medical staff from treating reform negatively.

\section{Ethics Approval and Consent to Participate}

This study protocol was approved by the Ethics Committee of Tongji Medical College, Huazhong University of Science and Technology (IORG No: IORG0003571). In addition, the study was in accordance with the 1964 Declaration of Helsinki and its later amendments or comparable ethical standards. Verbal informed consent was obtained by medical staff from each participant before the original survey.

\section{Funding}

This work was supported by Major Key Research Projects in Philosophy and Social Sciences of the Ministry of Education of the People's Republic of China [18JZD044], Startup Fund for Young Faculty at SJTU (SFYF at SJTU) [21X010501076] and Hospital Management Project at CHDI of SJTU [CHDI-2021B-48].

\section{Disclosure}

The authors report no conflicts of interest in this work.

\section{References}

1. Iganski P, Mason D. Ethnicity, Equality of Opportunity and the British National Health Service. Taylor and Francis; 2018.

2. Zhong D. The international experience and trend of public hospital governance reform. China Inst Reform Manage. 2016;7:34-36.

3. Wang $\mathrm{H}$. The cycle of medical reform: structured analysis based on the practice of medical reform in 15 countries over a hundred-year period. Comp Econ Soc Syst. 2012;2012(04):32-43.

4. Okma Kieke G, Luca C, Tim T. Health Reforms Across the World: The Experience of Twelve Small and Medium-Sized Nations with Changing Their Healthcare Systems. World Scientific Publishing Company; 2020.

5. Ozcan YA, Khushalani J. Assessing efficiency of public health and medical care provision in OECD countries after a decade of reform. Central Eu J Operations Res. 2017;25(2):325-343. doi:10.1007/ s10100-016-0440-0

6. Hu D, Wang X, Jiang R, Chen J. Performance evaluation of medical services in nine urban public hospitals based on patient reported experience: a cross-sectional survey. Lancet. 2018;392:S72.

7. Li C, Yu C. Performance evaluation of public non-profit hospitals using a bp artificial neural network: the case of Hubei Province in China. Int J Env Res Pub He. 2013;10(8):3619-3633. doi:10.3390/ ijerph10083619

8. Commission, N.H.A.F. 2020 China Health and Family Planning Statistics Yearbook. Beijing: China Union Medical University Press; 2021.

9. Guan X, Qi L, Liu L. Controversy in public hospital reforms in China. Lancet Global Health. 2016;4(4):e240. doi:10.1016/S2214109X(16)00041-3

10. Huang J, Dai T. Public hospital reforms in China: the perspective of hospital directors. BMC Health Serv Res. 2019;19(1):142. doi:10.1186/s12913-019-3954-z 
11. Liu GG, Vortherms SA, Hong X. China's Health Reform Update. Annu Rev Publ Health. 2017;38(1):431-448. doi:10.1146/annurevpublhealth-031816-044247

12. Fu H, Li L, Yip W. Intended and unintended impacts of price changes for drugs and medical services: evidence from China. Soc Sci Med. 2018;211:114-122. doi:10.1016/j.socscimed.2018.06.007

13. Zhang $\mathrm{H}$, Hu $\mathrm{H}$, Wu C, Yu H, Dong H. Impact of China's public hospital reform on healthcare expenditures and utilization: a case study in ZJ province. PLoS One. 2015;10(11):e143130.

14. Yip W, Fu H, Chen AT, et al. 10 years of health-care reform in China: progress and gaps in Universal Health Coverage. The Lancet. 2019;394(10204):1192-1204. doi:10.1016/S0140-6736(19)32136-1

15. Yip W, Hsiao WC, Chen W, Hu S, Ma J, Maynard A. Early appraisal of China's huge and complex health-care reforms. The Lancet. 2012;379(9818):833-842. doi:10.1016/S0140-6736(11)61880-1

16. Li L, Fu H. China's health care system reform: progress and prospects. Int $J$ Health Plann Manage. 2017;32(3):240-253. doi:10.1002/hpm.2424

17. Nong S, Yao NA. Reasons behind stymied public hospital governance reform in China. PLoS One. 2019;14(9):e222204. doi:10.1371/ journal.pone.0222204

18. Zhang P. Public hospital reform and the principal roles of medical staff. Cell Biochem Biophys. 2015;72(1):89-92. doi:10.1007/s12013014-0409-3

19. Doherty C. A qualitative study of health service reform on nurses' working lives: learning from the UK National Health Service (NHS). Int $J$ Nurs Stud. 2009;46(8):1134-1142. doi:10.1016/j.jinurstu.2009.01.014

20. Mattarelli E, Tagliaventi MR. How offshore professionals' job dissatisfaction can promote further offshoring: organizational outcomes of job crafting. J Manage Stud. 2015;52(5):585-620. doi:10.1111/ j.1467-6486.2012.01088.x

21. Ross J, Jones J, Callaghan P, Eales S, Ashman N. A survey of stress, job satisfaction and burnout among haemodialysis staff. J Ren Care. 2009;35(3):127-133. doi:10.1111/j.1755-6686.2009.00102.x

22. Yu X, Zheng M, Cheng X, et al. Job satisfaction among doctors from Jiangsu Province in China. Med Sci Monit. 2018;24:7162-7169. doi:10.12659/MSM.912712

23. Commission, N.D.A.R. Reply of the National Development and Reform Commission on Supporting Wuhan to Build a National Central City. Vol. 2018; 2017.

24. Council, O.O.T.S. Guiding Opinions of the General Office of the State Council on the Pilot Reform of Urban Public Hospitals. Vol. 2018; 2018.

25. Li L, Hu H, Zhou H, et al. Work stress, work motivation and their effects on job satisfaction in community health workers: a cross-sectional survey in China. BMJ Open. 2014;4(6):e4897. doi:10.1136/bmjopen-2014-004897

26. Meng R, Li J, Zhang Y, et al. Evaluation of patient and medical staff satisfaction regarding healthcare services in Wuhan Public Hospitals. Int J Env Res Pub He. 2018;15(4):769. doi:10.3390/ijerph15040769

27. Zhou H, Han X, Zhang J, et al. Job satisfaction and associated factors among medical staff in tertiary public hospitals: results from a national cross-sectional survey in China. Int J Environ Res Public Health. 2018;15(7):1528. doi:10.3390/ijerph15071528
28. Liping L. Reflections on the humanistic care of doctors under the background of new medical reform. Hum Resour Manage US. 2018;24:P224-P225.

29. Konrad TR, Williams ES, Linzer M, et al. Measuring physician job satisfaction in a changing workplace and a challenging environment. Med Care. 1999;37:11. doi:10.1097/00005650-199911000-00010

30. Tsai YH, Huang N, Chien LY, Chiang JH, Chiou ST. Work hours and turnover intention among hospital physicians in Taiwan: does income matter? BMC Health Serv Res. 2016;16(1):667. doi:10.1186/s12913016-1916-2

31. Huang J. The key point of public hospital reform: based on the investigation and research of public hospital presidents. Chinese J Health Policy. 2017;10:41-45.

32. Song Y, Xie Y. A survey on job satisfaction of doctors and nurses from a hospital in Anshan. $J$ Chin Mod Nurs. 2008;17:49-51.

33. $\mathrm{Lu} \mathrm{Y,} \mathrm{Hu} \mathrm{X,} \mathrm{Huang} \mathrm{X,} \mathrm{et} \mathrm{al.} \mathrm{Job} \mathrm{satisfaction} \mathrm{and} \mathrm{associated} \mathrm{factors}$ among healthcare staff: a cross-sectional study in Guangdong Province, China. BMJ Open. 2016;6:e113887. doi:10.1136/bmjopen-2016-011388

34. Du W, Luo Z. Job satisfaction study before and after medical reform in medical staff in public hospitals-evidence from S City. Hubei Soc Sci. 2018:82-87. Chinese. doi:10.13660/j.cnki.42-1112/c.014497

35. Jinglei W. Salary reform: taking assessment as the core and promoting growth through dynamics. Chin Health. 2018;27-28. doi:10.5582/bst.2017.01198

36. Liu J, Miao J, Zhang D. Dilemma of healthcare reform and invention of new discipline of health fiscalogy. Global Health Res Pol. 2016;1 (1):4. doi:10.1186/s41256-016-0003-x

37. Luo Q, Wang Q, Lu Z, Liu J. Evaluation of responsiveness of community health services in Urban China: a quantitative study in Wuhan City. PLoS One. 2013;8(5):e62923. doi:10.1371/journal. pone. 0062923

38. Statistics, W.M.B.O. Wuhan Statistical Yearbook. Beijing: China Statistics Press; 2017.

39. Commission, W.H.A.F. Report of Wuhan Municipal People's Government on the Comprehensive Reform of Public Hospitals. Vol. 2018; 2018.

40. Li L. The basic Theory and international experience of graded diagnosis and treatment system. Health Econ Res. 2018. Chinese. doi:10.14055/j.cnki.33-1056/f.20180109.019

41. Zhao Q, Zx MJ. Survey of career satisfaction and physical/mental health of medical workers in China. Chin $J$ Hosp Admin. 2016;32:438-440.

42. Tang W, Xie J, Lu Y, Liu Q, Malone D, Ma A. Effects of Chinese urban public hospitals reform on revenue and compensation after removing drug markups: case of Nanjing. J Med Econ. 2017;1-31.

43. Zhou XD, Li L, Hesketh T. Health system reform in rural China: voices of healthworkers and service-users. Soc Sci Med. 2014;117:134-141. doi:10.1016/j.socscimed.2014.07.040
Risk Management and Healthcare Policy

\section{Publish your work in this journal}

Risk Management and Healthcare Policy is an international, peerreviewed, open access journal focusing on all aspects of public health, policy, and preventative measures to promote good health and improve morbidity and mortality in the population. The journal welcomes submitted papers covering original research, basic science, clinical \& epidemiological studies, reviews and evaluations, guidelines, expert opinion and commentary, case reports and extended reports. The manuscript management system is completely online and includes a very quick and fair peer-review system, which is all easy to use. Visit http://www.dovepress.com/testimonials.php to read real quotes from published authors. 